\title{
EVALUATING THE SCALE FACTORS OF PEDO-TRANSFER MODELING THE SOIL WATER CHARACTERISTIC CURVE OF ZAKHO SOILS.
}

\author{
NAJdAT SABri ABdulkhaliQ \\ College of Engineering, University of Duhok, Kurdistan Region-Iraq
}

\begin{abstract}
The soil-water characteristic curve is the basis for estimating unsaturated soil properties. The negative pore pressure measurement is costly, time consuming, and needs accurate techniques to be measured. However, the pedo-transfer modeling of Arya and Paris introduces solution for the problem. The constant, linear, and Vaz scaling techniques in association with Arya and Paris model was used to predict SWCC from particle-size distribution. A total of 48 soil suction vs. volumetric water content experimental tests representing the SWCC for five different regions of Zakho district was processed for this purpose. The scaling parameters were obtained and the results show that linear and constant techniques have interpret the experimental results of the SWCC with appreciable confidence, however Vas scaling method is not recommended to be used for Zahko soil for the relatively weak correlations obtained.
\end{abstract}

KEYWORDS: Unsaturated soils, Pedo-transfer, Soil-water characteristic curve.

\section{INTRODUCTION}

$\mathbf{T}$ The soil-water characteristic curve (SWCC) is defined as the relationship between volumetric moisture content $(\theta)$ and matric suction $\left(U_{a}-U_{w}\right)$ in unsaturated soils. The soilwater characteristic curve comprises important information regarding the amount of water occupied in the pore spaces at any soil suction situation and the pore size distribution related to the state of the stresses in the soil-water system.

The (SWCC) is considered as the key soil information required for the analysis of shear strength, volume change and seepage problems involving unsaturated soils (Fredlund, 2006). For example, in seepage analysis problem, the permeability function is directly related to the SWCC. Furthermore, with the aid of the SWCC, the constitutive relations related the volume change and shear strength of saturated soils turns out as constitutive surfaces for unsaturated soils. Hence, it is necessary that the relationship to be well measured and/or interpreted.

The constitutive relationships that process the concepts of unsaturated soils have been proposed in the classic view of interest of soil mechanics and foundation engineers, while the application or implementation into engineering practice has been slow (Fredlund, 1997). One of the reasons for the delay in the application of unsaturated soil mechanics in practice is the time consuming for the determination of the SWCC in the laboratory, and also the specialized equipment and training required. Hence, because of its importance and contribution in the wide spectrum of unsaturated soils problems researchers prompted to find an alternative ways to determine the SWCC via laboratory testing; one of the methods that estimates or derives the SWCC based on basic known soil indices is Arya and Paris (AP) 1981.

The pedo-transfer modeling method proposed by Arya and Paris predicts the soil water characteristics curve for soils in its natural packing using basic properties namely, the grain size distribution, and bulk density. The assumption of Arya-Paris model is that the soil water characteristics curve is strictly relates the pore size distribution curve while, the pore-size distribution in turns is determined essentially by the particlesize distribution and bulk density of the soil.

Modeling the soils water characteristic curve using AP method requires transferring the hypothesis of the idealized soil grains proposed to real soil structure by processing of certain scaling factor. Many different approaches have been used to derive such scale factor. The study focuses on testing and evaluating three different procedures of deriving the scale factor associated with the modeling the SWCC for Zakho soils.

Arya and Paris model algorithm: -

The first pedo-transfer method to estimate the SWCC is presented by Arya and Paris (1981), 
they stated that the basic information for the model is the grain size distribution curve and the volumetric water content was assessed depending on an estimation of the pore size distribution of the soil. (Fredlund, M. D., et al. (2002).

The model treats the water flow paths in a soil as a bundle of capillary tubes and assumes that the size of the soil particles is related to the corresponding pore diameters of the capillary tubes that in turn becomes a function of the mass fraction of the particle size with scaling parameter is to be used to involve account for uncertainties in the estimation. (Heshmati and Motahari, 2012).

The distribution of pores from a grain size distribution is processed as follows: The particle size distribution curve was grouped into several fractions representing a number of classes of size of particles. The pore volume per unit sample mass corresponding to the solid particles in the ith group,

$$
V_{v_{i}}=\left(\frac{W_{i}}{\rho_{b}}\right) \cdot e=\pi r_{i}^{2} h_{i} \quad ; i=1,2,3, \ldots, n
$$

Where:

$W_{i}, \quad$ is the solid mass per unit sample mass in the $i$-th particle-size range. $\rho_{b}$ is the particle density.

$r_{i} \quad$ is the mean radius of the proposed cylindrical pores.

$h_{i} \quad$ is the pore length.

$e \quad$ is the void ratio.

Starting with the first group fraction (smallest particles), the calculated pore volumes are progressively accumulated and considered to be filled with water. Each accumulation of filled pore volume is divided by the bulk volume of the whole sample to obtain volumetric water content $(\theta)$ at the upper bound of the successive groups.

$$
\begin{aligned}
& \theta_{i}=\sum_{j=1}^{j=i} V_{v_{j}} / V_{b} \\
& V=\sum_{j=1}^{j=i} W_{i} / \rho_{b}=1 / \rho_{b}=n_{i} \cdot(4 / 3) \cdot \pi R_{i}^{3}
\end{aligned}
$$

As $V$ is the bulk volume of the soil unit mass $W_{i}$ and $n_{i}$ are the weight and number of the $i$-th particlesize range respectively.

$$
\theta_{i}^{*}=\left(\theta_{i}-\theta_{i+1}\right) / 2
$$

Where: $\theta_{i}^{*}$ is the volumetric moisture content representing the abscissa of the soil water characteristic curve.

$$
\text { Now, } e=\frac{\pi r_{i}^{2} h_{i}}{n_{i} \cdot(4 / 3) \cdot \pi R_{i}^{3}}
$$


The fraction of size $\left(R_{i}\right)$ is proposed to consist of spherical solid particles, in which each fraction class is assembled to form a cubic close-packed structure consisting of uniform-sized spherical particles. The bundle of capillary tubes utilized to process (AP) model have been related to the size of soil particles that in turn related to the corresponding pore are assumed to have length of $h_{i}=2 . n_{i}^{\alpha} R_{i}$, Figure (1) shows the schematic representation the scale factor $(\alpha)$, which has value of (1.0) for a linear pore water distribution while its value for random distribution of particle sizes in natural soils is to be scaled.

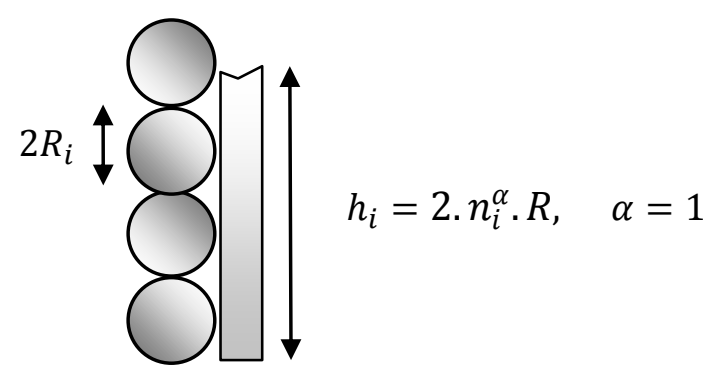

Fig. (1): the schematic representation for rectilinear arrangement of spherical particles.

$$
\begin{aligned}
\frac{r_{i}^{2}}{R_{i}^{3}} & =\frac{n_{i} \cdot(4 / 3) \cdot e}{h_{i}}=\frac{n_{i \cdot(4 / 3) \cdot e}}{2 \cdot n_{i}^{\alpha} R} \\
r_{i} & =R_{i} \cdot\left(\frac{2}{3} e \cdot n_{i}^{1-\alpha}\right)^{1 / 2}
\end{aligned}
$$

Where: $r_{i}$ mean pore radius, and $\alpha$ is an empirical factor greater than 1.0.

Once the pore radii are obtained for all the classes particle sizes, the equivalent soil suction then, is to be calculated using the equation of capillarity.

$$
u=\frac{2 T_{S} \cdot \cos \psi}{\rho_{w} \cdot g \cdot r_{i}}
$$

$$
\text { Where: }
$$

u : soil suction;

$T_{S} \quad$ : surface tension of water;

$\psi \quad$ : contact angle;

$\rho_{w} \quad:$ density of water, and

$g \quad$ : acceleration due to gravity.

\section{Experimental Work: -}

Bulk density, particle size distribution, saturated water content $\left(\theta_{\text {sat }}\right)$ and some other physical properties of (5) soil samples from Zakho discrete were measured using standard techniques.
All the specimens are extracted from depth of 0.8 $\mathrm{m}$ from the ground surface in natural state. Table (1) is shows the regions of Zakho at which the soil samples have been extracted and summarizing the salient properties of the Zakho soils used. 
Table (1): the salient physical properties of the soils used.

\begin{tabular}{cccccccccc}
\hline Properties & $\begin{array}{c}\text { Bulk } \\
\text { density } \boldsymbol{\rho}_{\boldsymbol{b}}\end{array}$ & Gs & Gravel\% & $\begin{array}{c}\text { Sand } \\
\%\end{array}$ & $\begin{array}{c}\text { Silt } \\
\%\end{array}$ & $\begin{array}{c}\text { Clay } \\
\%\end{array}$ & LL & PI & $\boldsymbol{\theta}_{\boldsymbol{s}} \%$ \\
\hline Region & 1.69 & 2.69 & 9 & 36 & 43 & 12 & 48 & 19 & 38.0 \\
\hline Bedar & 1.81 & 2.70 & 0 & 23 & 60 & 17 & 59 & 23 & 33.1 \\
\hline Tel Kaber & 1.80 & 2.69 & 1 & 15 & 72 & 12 & 58 & 23 & 33.8 \\
\hline Ibraheem Al-Khalil & 1.73 & 2.69 & 15 & 36 & 39 & 10 & 45 & 18 & 39.9 \\
\hline Rekawa & 1.75 & 2.71 & 1 & 25 & 47 & 27 & 62 & 23 & 34.9 \\
\hline Shkaft Mara & & & & & & & &
\end{tabular}

Since, the range of soil suction that to be imposed is wide, two complimentary methods of imposing suction have been used for obtaining the soil water characteristic curve. Figure (2)
Designating the methods adopted for the full range of soil suction values. Figure (3) shows the experimentally measured SWCC data for the Zakho soils used.



Figure (2) the methods used for the entire range of soil suction.

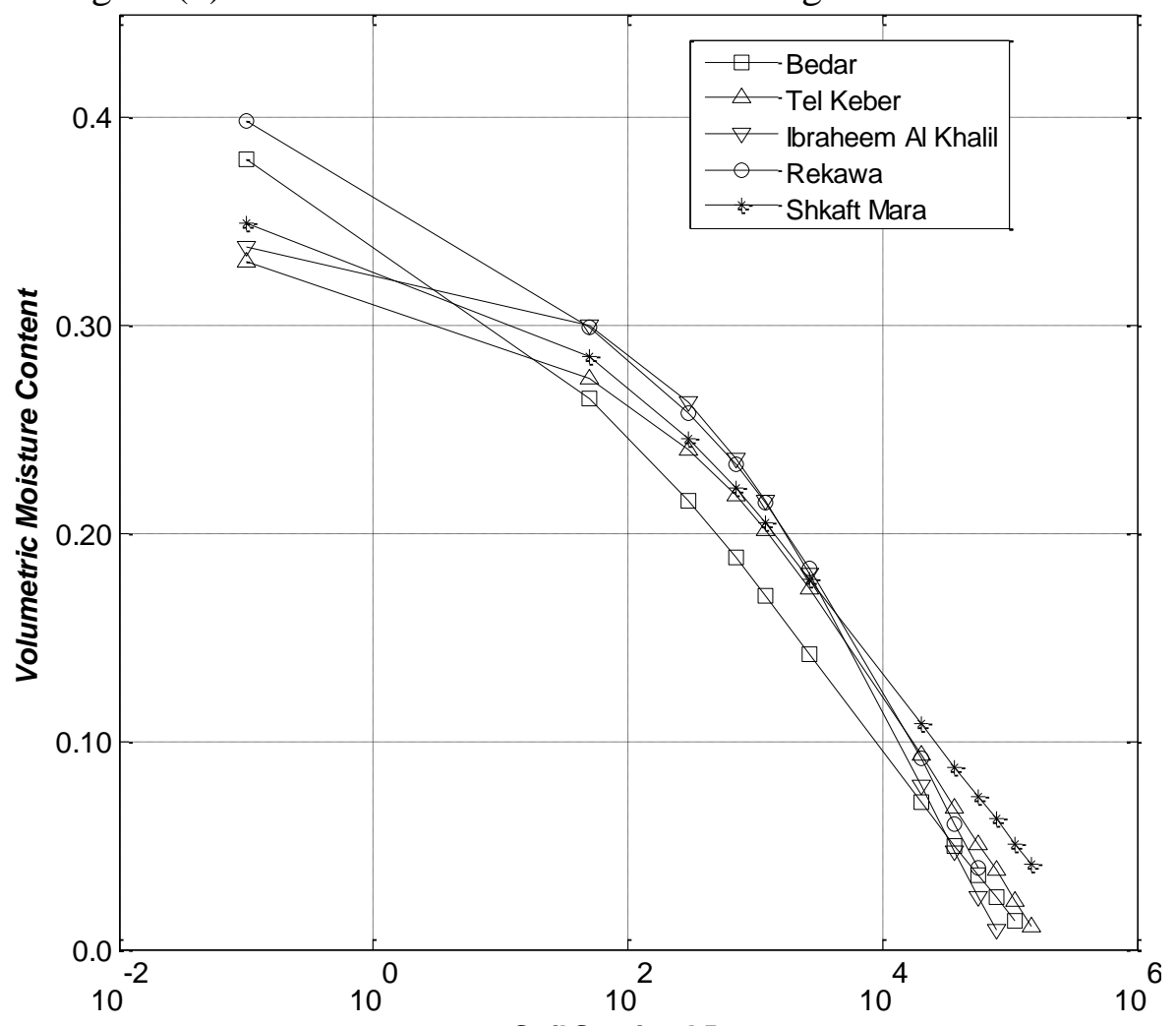

Soil Suction $k P a$.

Fig. (3): the experimentally measured SWCC data for Zakho soils.

With the Osmotic Membrane Method, special membrane arranged in small plastic bags with soil specimens inside that is soaked in a different concentration of poly-ethylene glycol (P.E.G.); each concentration impose different suction value the membrane allows the moisture movement in one direction only until equilibrium is attained to the suction of the soil specimen (Tripathy and Rees, (2013). The volumetric moisture contents 
obtained by this method are those associated with suction values of $1200,700,50$, and $30 \mathrm{kPa}$.

The rest of suction range is imposed by the Humidity Control Method. To reach different water suction values, soil samples were equilibrated across a vapor gap with different salts solutions of known relative humidity and osmotic suction potential. The soil and the salt solution are placed in desiccators for insulation. At equilibrium, the water content of the soil samples can be determined by oven-drying (Mantikos, et al. 2016). The volumetric moisture contents obtained by this method are those associated with suction values of $150,111,78,57,37,20$, and 2.7 MPa.

\section{Estimation of scaling factors $\alpha$ : -}

Several approaches have been used to scale $\alpha$ values to model the SWCC and that the curve becomes independent with soil properties (Gitirana and Fredlund, 2004). One of the methods used to estimate the scale factor $(\alpha)$ is the constant method which can be obtained utilizing the relationship between the number of particle in natural soil $\left(\mathrm{N}_{\mathrm{i}}\right)$ the numbers of spherical particles $\left(\mathrm{n}_{\mathrm{i}}\right)$ for ideal soil as given in the following equation:

$$
N_{i}=n_{i}^{\alpha}, \alpha=\frac{\log N_{i}}{\log n_{i}}
$$

Arya et al (1999) evaluated $\mathrm{N}_{\mathrm{i}}$ using the following expression: -

$$
N_{i}=7.371 W_{i} e \frac{h_{m}^{2}}{\rho_{s} R_{i}} \quad \text { (10) } \quad \text { and, } \quad n_{i}=\frac{1}{\rho_{b}(4 / 3) . \pi R_{i}^{3}}
$$

Where $h_{m}$ is the measured pressure head.

Another method suggested by the same researcher and also adopted by (S. Liu, et al,

$$
\alpha=\frac{a+b \log \left(\frac{W_{i}}{R_{i}^{3}}\right)}{\log n_{i}}
$$

2013) for the estimation of $\alpha$ is to linear fit between $\log \mathrm{N}_{\mathrm{i}}$ and $\log \frac{w_{i}}{R_{i}^{3}}$ as follows:
The constant values of the scale factor obtained by constant method and the linear parameter (a) and, (b) that obtained by the above methods are shown in Table

(2).

Table (2): the constant values and linear parameter for Zakho soils used.

\begin{tabular}{cccc}
\hline Region & Constant $\alpha$ & \multicolumn{2}{c}{ Linear Parameters } \\
\cline { 3 - 4 } & & $a$ & $b$ \\
\hline Bedar & 1.345 & -1.321 & 1.398 \\
\hline Tel Kaber & 1.325 & -2.031 & 1.420 \\
\hline Ibraheem Al-Khalil & 1.315 & -0.983 & 1.346 \\
\hline Rekawa & 1.485 & -0.993 & 1.498 \\
\hline Shkaft Mara & 1.316 & -1.713 & 1.389 \\
\hline
\end{tabular}

(Vaz et al. 2005), appraise the performance of the AP model by employing an expression for $\alpha$ as a function of the soil volumetric water content, $(\theta)$; as

$$
\alpha_{i}=0.947+0.427 e^{\left(\frac{-\theta_{i}}{0.129}\right)}
$$

The aforementioned scaling methods have been utilized in association with the Arya and Paris algorithm for estimation the soil water characteristic curve relationships for the soil specimens of Zakho city. 


\section{RESULTS AND DISCUSSION}

To evaluate the accuracy of the three adopted methods of scaling factors for Zakho soils, correlations between the data of experimentally measured and estimated volumetric moisture contents with their associated suction values were calculated via the coefficient of determination $\left(R^{2}\right)$ and Normalized root mean square error(NRMSE) as evaluation criteria. The correlations are demonstrated in Table (3) while the formula for determining the correlation values are:

$$
\begin{aligned}
& R^{2}=1-\frac{\sum_{1}^{n}\left(y_{i}-\breve{y}_{i}\right)^{2}}{\sum_{1}^{n}\left(y_{i}-\bar{y}_{i}\right)^{2}} \\
& (N R M S E)=\sqrt{\frac{\sum_{1}^{n}\left(y_{i}-\breve{y}_{i}\right)^{2}}{N}} / \bar{y}_{i}
\end{aligned}
$$

Where:

$\begin{array}{ll}y_{i} & : \text { Experimentally measured volumetric water content, } \\ \bar{y}_{i} & : \text { Estimated volumetric water content by the different methods, } \\ \bar{y}_{i} & : \text { The mean measured volumetric water content and, } \\ \mathrm{N} & : \text { Number of pairs of volumetric water content. }\end{array}$

Table (3): Values of $R^{2}$ and NRMSE for the methods of estimating the volumetric moisture contents

\begin{tabular}{lccc}
\hline & Constant & Linear & Vaz \\
\hline$R^{2}$ & 0.980431 & 0.983008449 & 0.535391 \\
\hline NRMSE & 0.092897 & 0.086562757 & 0.452646 \\
\hline
\end{tabular}

The Normalized mean root square error NMRSE value is often expressed as a percentage, where lower values indicate less residual variance. The results in Table (3) show that the estimated soil water retention curve for Zakho selected soils using the linear $\alpha$ and constant $\alpha$ methods agree well with the experimentally measured soil water characteristics curve, in contrast, the evaluation criteria do not show adequate values for $\mathrm{Vaz}$ scaling method. The relatively slight difference in NRMSE and the adequate coefficient of determination for both the constant method and linear method may encourages the use the constant method for simulating the SWCC for Zakho city.

In order to demonstrate the robustness of the selected three scaling methods the eccentricity of the data of volumetric moisture contents measured by the scaling methods relative to the experimental moisture contents were expressed via histograms, the data are binned into 10 distinct eccentricity levels as shown in Figure (4).

The histograms show the relative frequency for the number of occurrence of the data of $\left(\vartheta_{\text {Met } \square o d} / \vartheta_{\text {exp }}\right)$ surrounding (1.0) are about 32,
29, and 4 for the constant, linear and Vaz methods respectively. In addition, better performance is shown regarding the standard deviation and mean, for the constant, linear in lieu of Vaz method in sequence.

The Figures (5) also demonstrate the data of the experimentally tested volumetric moisture content $\vartheta$ versus those measured by the three scaling factors using 1:1 plot. One certain conclusion, in addition to that the linear and constant methods is better interpolate the soil water characteristic curve, is that all the constant and linear methods is underestimate the volumetric moisture content at low values (high suction) and vice versa. However, Vas method underestimates the estimation almost all of the values.

The scaling values using constant method show narrow range that is between 1.315 and 1.345 except the value of 1.485 for Rekawa soils, this may be attributed to the lower plasticity index and greater gravel percentage for that soil with respect the rest of the investigated soils. 
(a)


Fig. (4): Histogram of the relative frequency for volumetric moisture contents using (a) constant, method, (b) linear method, and (c) Vaz methods. 

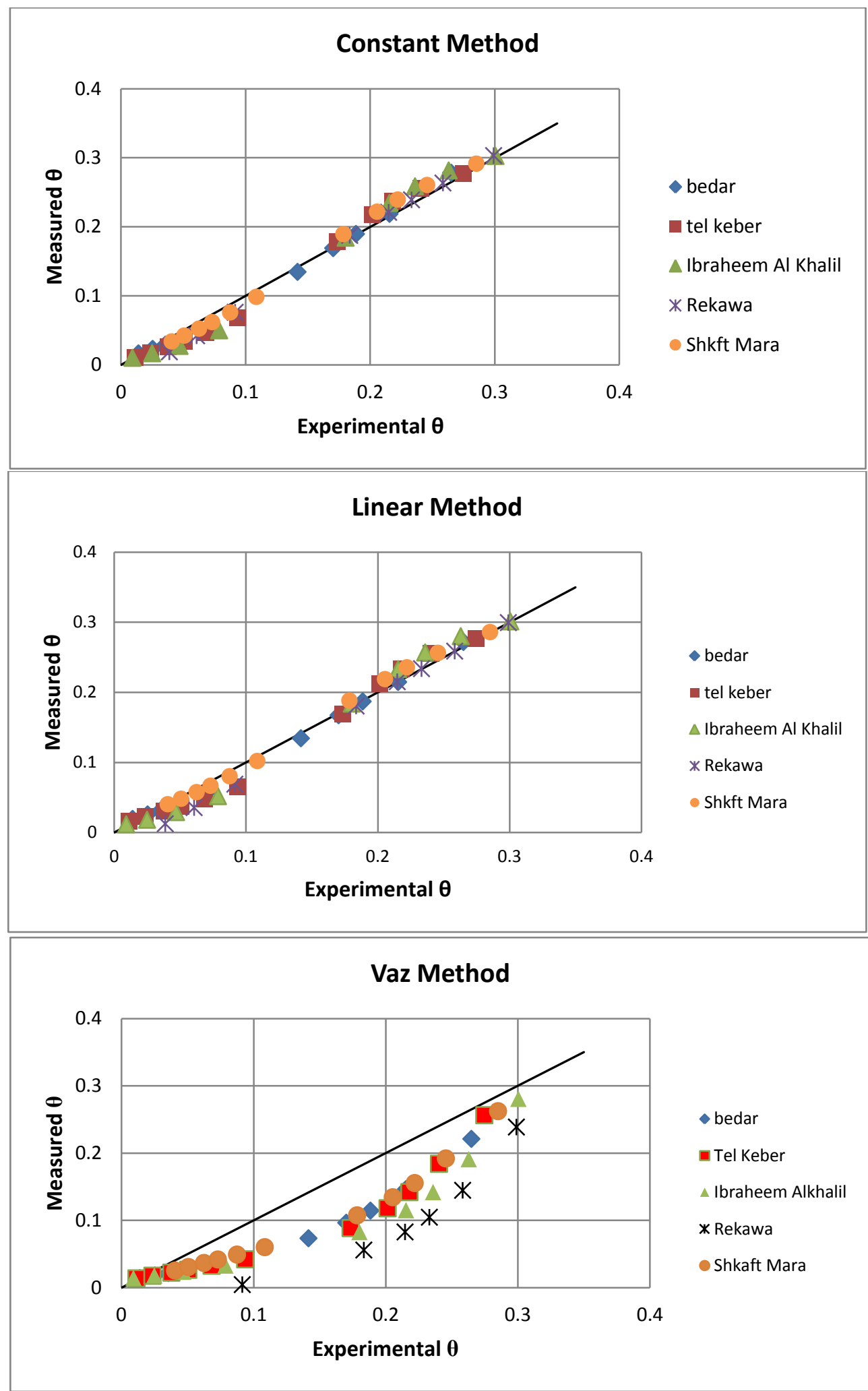

Fig. (5) 1:1 plot of the volumetric moisture contents using (a) constant method, (b) linear method, and (c) Vaz methods. 


\section{CONCLUSIONS}

The constant, linear, and Vaz scaling techniques in association with Arya and Paris model were adopted to predict SWCC from particle-size distribution. The parameters were obtained and the results show that linear and constant techniques have interpret the experimental results of the SWCC with appreciable confidence, this is not true for Vaz scaling method; so that it is not recommended to be used for Zahko soils. There was narrow range for the scaling values using constant method of 1.315 to 1.345 , except the value of 1.485 for Rekawa soil.

\section{REFERENCES}

- Arya, L.M., \& Paris J.F. (1981) “A Physicoempirical Model to Predict the Soil Moisture Characteristic from the Particle-Size Distribution and Bulk Density data, Soil Science Soc. American Journal, Vol. 45. pp. 1023-1030.

- Arya, LM, Leij FJ, van Genuchten MTh, Shouse PJ (1999). "Scaling parameter to predict the soil water characteristic from particle-size distribution data”. Soil Sci. Soc. Am. J., 63: pp. 510-519.

- Fredlund, M.D., Wilson, G.W., \& Fredlund, D.G. (2002). "Use of the Grain-Size Distribution for Estimation of the Soil-Water Characteristic Curve", Canadian Geotechnical Journal, Vol. 39, No. 5. pp. 1103-1117.

- Fredlund, D.G. (1997). "An Introduction for Unsaturated Soil Mechanics", ASCE, Geotechnical Engineering Division, Geo Logan
Conference, Special Geotechnical Publication, (68), 1-37.

- Fredlund, D.G. (2006). "Unsaturated Soil Mechanics in Engineering Practice", Journal of Geotechnical and Geo-environmental Engineering, Vol. 132, No. 3. pp. 286-321.

- Gitirana Jr. G., \& Fredlund, D.G. (2004). "Soil Water Characteristic Curve Equation with Independent Properties", Journal of Geotechnical and Geoenvironmental Engineering, Vol. 130, No. 2, pp. 209-212.

Heshmati, A.A. \& M.R. Motahari. (2012). "Identification of key parameters on Soil Water Characteristic Curve". Life Sci. J.; 9(3):15321537, (ISSN: 1097-8135).

- Liu, N. S. Y., Yasufuku, Q. Liu, and J. Yu, (2013). "Prediction of Soil Water Characteristic Curve Using Physically Based Scaling Technique. Lowland Technology International, Vol. 15, No. 1.

- Mantikos, S. Ackerley, A. Kirkham, A. Tsiampousi, D.M.G. Taborda and J. Standing. (2016). "Investigating soil water retention characteristics at high suctions using relative humidity control". 3rd European Conference on Unsaturated Soils (E-UNSAT), Publisher: E. D. P. SCIENCES, ISSN: 2267-1242

- Tripathy, S. Rees, S. W., (2013). "Suction of Some Polyethylene Glycols Commonly Used for Unsaturated Soil Testing," Geotechnical Testing Journal, Vol. 36, No. 5, 2013, pp. 768-780.

- Vaz, C.M.P., Iossi, M.D.F., Naime, J.D.M., Macero, A., Reichert, J.M., Reinert, D.J. and Cooper, M. (2005). "Validation of the Arya and Paris water retention model for Brazilian soils". Soil Sci. Soc. Am. J. 69(3): 577-583. 